Understanding road traffic risks from the street hawker's perspective Peer-reviewed author version

SAM, Enoch; Akansor, Justina \& Agyemang, William (2018) Understanding road traffic risks from the street hawker's perspective. In: International Journal of Injury Control and Safety Promotion,.

DOI: $10.1080 / 17457300.2018 .1482925$

Handle: http://hdl.handle.net/1942/27198 


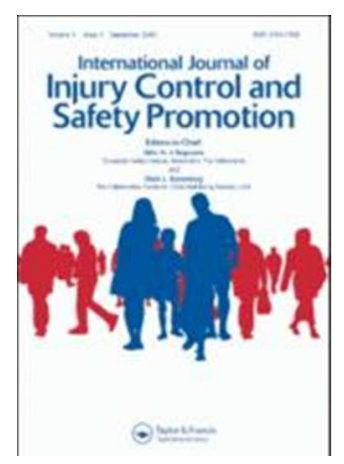

\section{Understanding road traffic risk from the street hawker's perspective}

\begin{tabular}{|r|l|}
\hline Journal: & International Journal of Injury Control and Safety Promotion \\
\hline Manuscript ID & NICS-2017-0124.R3 \\
\hline Manuscript Type: & Original Research Article \\
\hline Date Submitted by the Author: & n/a \\
\hline Complete List of Authors: & $\begin{array}{l}\text { Sam, Enoch; Univ Educ, Geography Education; Hasselt University, } \\
\text { Transportation Research Institute } \\
\text { Akansor, Justina; University of Education, Winneba, History Education } \\
\text { Agyemang, William; Building and Road Research Institute }\end{array}$ \\
\hline Keywords: & $\begin{array}{l}\text { Traffic risk, Street hawkers, Accidents, Road crossing, Traffic risk } \\
\text { perception and handling }\end{array}$ \\
\hline \multicolumn{2}{|c}{} \\
\hline
\end{tabular}




\title{
Understanding road traffic risks from the street hawker's perspective
}

\begin{abstract}
This study explored street hawkers' lived experiences and risks in traffic using the phenomenological case study design. Data from 24 hawkers at three hawking spots and field observations form the basis of our study. A stratified purposeful sampling scheme was employed to ensure a balance of gender and age. Thematic data analytic strategy was employed in data analysis.

We found that participants' traffic incidents were mainly self-induced, attributable to their negligence on the road, indiscriminate road crossing and car-following behaviour. Our results suggest a perceived relationship between socio-demographic characteristics and personal traffic accident encounters. Also, we noted that the ability to manage traffic risk seem to influence hawkers' traffic risk perceptions, with gender and age as possible mediators. As this study is exploratory, we recommend further scientific enquiry to explain these issues and to provide the basis for appropriate interventions to manage the road safety implications of this activity.
\end{abstract}

\section{Keywords}

Traffic risk; street hawkers; accidents; road crossing; traffic risk perception and handling 


\section{Introduction}

It is common knowledge that hawking (defined as the selling of goods in the public spaceSkinner, 2008; Mitullah, 2003) in traffic is unsafe, with possible risk ranging from injuries and death as a result of knockdowns by vehicles. Even though this is the unfortunate reality, it is yet to be prioritised as a social problem in Ghana, where the trade is widespread. However, some studies have been done on this phenomenon in Nigeria (Ayodele \& OlubayoFatiregun, 2014; Nduka \& Duru, 2014) where the trade pertains as well. The trade is common in most urban centres in Africa (Skinner, 2008; Mitullah, 2003). In their study "The menace of street hawking in Aba metropolis, South-East Nigeria”, Nduka and Duru (2014) observed that unemployment and poverty were major determinants of street hawking. On the traffic risk associated with street hawking, they revealed that 214 (83 males and 131 females) of their respondents had once been victims of road traffic accidents as street hawkers; this affirming the claim that street hawking is unsafe.

On their part, Ayodele and Olubayo-Fatiregun (2014) investigated accidental injuries among juvenile hawkers in Nigeria. They reviewed literature (non-empirical study) on the injury risk behaviours of juvenile hawkers, their accidental injuries and its implications for socioeconomic development. They observed that the poor socio-economic status of many families in the country underscore children's involvement in hawking. Based on their reviews, they recommended that governments prioritise poverty alleviation, education of parents on the menace of juvenile hawking, and the prioritisation of children's' education. They advocated, however, for the legalisation, and moderation of the activities of street hawkers by the government especially where total eradication is not feasible. These findings provided justification for this study and also informed the questions asked during the field interviews and the a priori data coding strategy adopted for this study. 
Previous studies conducted on street hawkers in Ghana focused on the socioeconomic and reproductive health implications of their activities and the need for intervention programmes to equip them with employable skills (Kwankye, Nyarko \& Tagoe, 2007; Asare, 2010; Adaawen, 2011; Steel et al., 2014). Street hawkers' safety from road traffic accidents and the road safety implications of their activity is unexplored.

Perhaps a major reason for the dearth of research in this domain is the unavailability of data on road traffic incidents (accidents and fatalities) involving street hawkers in the line of their business. Where data are available, they are aggregated and captured as pedestrian traffic incidents in general, thus masking the risks associated with hawking in traffic. However, regarding general pedestrian traffic injuries and death in Ghana, the national road safety commission (NRSC, 2010) revealed that the pedestrian continues to be the road user with the highest accident risk in Ghana since 1991. A total of 65,308 pedestrian casualties, which is $24.1 \%$ of the total annual road user casualties $(271,162)$, was recorded in the country from 1991-2010. Further, data from the Building and Road Research Institute (BRRI, 2015) of the Centre for Scientific and Industrial Research, Kumasi, Ghana indicate that there were 2,895 pedestrian-related accidents (associated with 898 fatalities) in Ghana in 2011 increasing to 3,026 (914 fatalities) in 2012 and slightly reducing to 2,638 (831 fatalities) in 2015.

It is from this backdrop that this study seeks to uncover the road traffic risks inherent in street hawking from the hawkers' own perspective. The study exposes the traffic risks that hawkers encounter in the line of their business. Our findings provide relevant evidence-based safety interventions and policies to manage the road safety implications of street hawking. Given the dearth of research in this area, the study findings hope to stimulate further related studies. 


\section{Methodology}

Human behaviour and the reasoning behind the behaviour at any point in time is complex and thus difficult to understand from a scientific (quantitative) viewpoint. However, the qualitative research methodology is adept at exploring the complexities of human behaviour, perceptions, attitudes and interactions and the meanings attached to these in a social setting (Clifton \& Handy, 2001) and thus 'allow a grasp of the individual's own explanations of behaviour and attitudes' (Beirao \& Cabral, 2007, p. 480).

This study employed a phenomenological case study design to explore and understand street hawkers' lived experiences regarding road traffic risks associated with hawking. In executing the study, an in-depth semi-structured interview and naturalistic observation of street hawkers' activities at three locations (study sites), Kasoa, Ngleshie Amanfrom and Winneba, on the Winneba-Kasoa highway of the Central Region of Ghana was done. As popular hawking spots along that road network, these locations attract a large number of hawkers. However, studies have shown that the highway is one of the major accident-prone roads in the country and as such poses a greater accident risk for these street hawkers (Sam, 2011; Abane, 2010). This single 2-lane carriageway $(31.1 \mathrm{~km}$ in length; $7.3 \mathrm{~m}$ wide with $2.5 \mathrm{~m}$ shoulders on both sides) is a section of the Accra-Cape Coast trunk road (a national route 1 (N1) road), which also forms part of the Trans-West African Highway network. It has a design speed of 80 (at rolling terrain) to $100 \mathrm{kph}$ (at flat terrain), and a $50 \mathrm{kph}$ speed limit at populated areas. In 2008, the Winneba-Kasoa road recorded a weighted average annual daily traffic (AADT) volume of 9,661 vehicles per day, comprising 37\% vehicles in the medium group and $4 \%$ in the heavy group respectively (see Obiri-Asare, 2016). The busy nature of the road is not surprising as the road connects many towns and villages in the region to Accra, the national capital. Table 1 presents road traffic accident severity at the three study sites in 2010. This data was taken from the region's 2010 list of top twenty accident prone 
sites. From the Table, Kasoa recorded the highest (39) incidents (associated with 2 deaths, and various degrees of injuries and property damage), followed by Ngleshie Amanfrom area and Winneba junction, ranking the first, third and fifteenth top accident sites in the region respectively.

Interview data from 24 street hawkers and field observations and notes formed the basis for an in-depth understanding of the road traffic risks associated with street hawking. A stratified purposeful sampling scheme (Sandelowski, 2000; Miles \& Huberman, 1994; Patton, 1990) was employed to classify the potential respondents in advance (based on gender and age) to ensure a balance of gender (male and female street hawkers) and age (youthful, middle-aged, and elderly street hawkers). The inclusion of both gender and age was to explore the gender and age dimensions to the perspectives on the topic. This is justified by previous findings on gender (Gustafson, 1992; DeJoy, 1992; Yagil, 1998) and age (Otani, Leonard, Ashford, Bushroe \& Reeder, 1992; Sivak, Soler, Trankle \& Spagnhol, 1989) differences in traffic risk perception, risk taking, and risk handling. Aside from the gender and age criteria, a potential participant should be a hawker plying the trade on the Winneba-Kasoa Highway. Thus the emphasis was on the actors (street hawkers), the setting (Winneba-Kasoa road network) and the events (hawking). At each study site, the researchers approached available hawkers and explained the study objective, and sought for participation in the study. Hawkers who consented to participate were selected. Thus, the selection of a participant was based on the willingness to participate. There is, however, a limit to the generalisability of the study outcome because of the possible peculiarity of the lived experiences of street hawkers on different road networks (settings). We admit there is a potential for bias arising from the participant selection. However, this bias was reduced to the minimum as the participant selection was based on clearly established criteria (age, gender and setting-specific criteria as indicated earlier). There is also a limit to the generalisability of the study outcome because of 
the possible peculiarity of the lived experiences of street hawkers on different road networks (settings).

Data collection involving interview schedules and field observations (extensive field observations and associated note-taking were done before and after the interview sessions) took place on three separate days: $29^{\text {th }}$ December $2014,17^{\text {th }}$ and $21^{\text {st }}$ January 2015 at Ngleshie Amanfrom (plaza toll booth), Kasoa (traffic light area) and Winneba junction respectively at three different time periods: 8 am to 9 am, $12 \mathrm{pm}$ to $2 \mathrm{pm}$ and $4 \mathrm{pm}$ to $6 \mathrm{pm}$. These time periods correspond to the morning rush hour, off-peak period and evening rush hour respectively. The morning and evening rush hour periods represent the peak of street hawking activities, as more vehicular traffic means more potential customers. However, traffic flow is relatively fast during the off-peak period, implying less trading activities. Nonparticipant observations done at these time periods (peak and off-peak) were to assess street hawkers' road crossing and car-following behaviour in the attempt to sell their wares or respond to calls from buyers, and manoeuvres in traffic. It is worth noting that prior observations made informed the questions asked during the field interviews. Table 2 present the observations made and notes taken during field data collection at the study sites. The majority of the instances observed related to hawkers' car-following and indiscriminate road crossing behaviour; which incidentally happen to be major risk factors for pedestrian traffic accidents in Ghana (NRSC, 2014).

An interview session lasted 20 minutes on average. Of the 24 interviews conducted, 7 were in Kasoa, 6 in Ngleshie Amanfrom and 11 in Winneba. At a point, we observed that further interviews yielded no new information (informational redundancy) (Glaser \& Strauss, 1967; Sandelowski, 1995) at which stage data collection was halted.

Aided by the Atlas.ti 7.0 software, data analysis followed the thematic data analytic strategy in a chronological manner involving data organisation, data coding and category generation. 
In organising the data, digitally-recorded field interviews were transcribed verbatim from participants' local dialects into the English language. An initial descriptive (topic) coding (see Miles \& Huberman, 1994) and subsequently focused coding (see Charmaz, 2006) were done. However, data coding followed the deductive coding style, informed by the study's research questions, prior observations and literature review. Field data, especially from the interviews, was presented using relevant, direct narratives and quotes (lived experiences in traffic) in line with the analytical procedures embedded within the phenomenological and case study designs. Data from the field observations and notes helped explain and give meaning to the various quotes and narratives.

The validity of information from study participants' was verified by data triangulation (through concurrent use of interviews, observation and field notes). Beyond this, through fact checking (member checking) we were able to confirm the authenticity of hawker-reported traffic incidents captured in this study. Thus, by asking hawkers to report on personal traffic incidents and those they might have witnessed or heard about, we were able to validate reported traffic incidents.

In the bid to establish the hawkers' perspectives on the traffic risks characteristic of street hawking, the following question was asked: What traffic risks do you face while hawking on the street?. As expected, the responses revealed that the hawkers were not oblivious of the traffic risks associated with the trade as the following quotes indicate: 'There are lots of risks involved. If one is not careful, he or she will be knocked down by a car' (Female, 25 years, Winneba). Another remarked: 'It is not easy with the moving cars; if you don't take care a car can knock you down' (Male, 22 years, Kasoa). As will be alluded to later, these risks usually result in injuries (both non-incapacitating and incapacitating) and death.

\subsection{Participants}


There were 18 females and 6 males in the study sample, consistent with the reality on the ground. In Ghana, petty trading, in general, is female-dominated as evident in Figures 1 and 2 (appendices). Their ages range from 14 years to 48 years, with more than half (16) between the ages of 21 and 40 years. The majority (10) had attained junior high school education at the time of the survey. Moreover, half of the sample were single and had traded for 1-5 years (13) as street hawkers (Table 3).

\section{Results and discussion}

The a priori themes (pre-determined themes) were participants' personal road traffic incidents, traffic incidents involving other hawkers as narrated by study participants, hawkers' in-traffic survival strategies and, gender and age variations in traffic risk perception and handling. Respectively, the first theme, participants' personal road traffic incidents, captured the participants' lived experiences regarding accidents and injuries in traffic in the course of their hawking activities; the second likewise sought to highlight traffic accidents and resulting injuries of other hawkers which the study participants have witnessed and/or heard about. Further, strategies adopted by the study participants to survive in the traffic environment in the course of their activities (third theme) and narratives and experiences detailing how the participants perceived and handled risk in the course of their hawking activities (fourth theme) were also elucidated.

\subsection{Participants' personal traffic incidents}

In exploring participants' personal encounters with the said risks (vehicle knockdowns) in the course of their trade, we probed 'what has been your personal experience(s) with road traffic incidents (accidents and injuries) since you started street hawking?' This afforded them the opportunity to narrate their personal lived experiences in traffic. We noted that 10 of the 
respondents (as indicated in Table 4; grouped by themes), 3 at Ngleshie Amanfrom, 2 at Kasoa and 5 at Winneba, had been victims of road traffic accidents while engaged in hawking, resulting in both non-incapacitating $(n=8)$ and incapacitating $(n=2)$ injuries. On the circumstances that led to their respective accidents, we noted two main causes; hawkerinduced (largely by victims'own actions and inactions) and external factors (victims through no fault of theirs). Regarding the former, we noted that in most cases, negligence on the part of hawkers, and motorists' inattention and/or disregard for road traffic rules and regulations caused the reported accidents:

I attempted crossing the road but I was not careful and the car knocked me down. I sustained some injuries. I was fortunate because the car was not at top speed. The result would have been more disastrous (Female, 31 years old).

This Saturday will mark one month since I was involved in an accident with a motorbike. Someone called me to buy "sarbo"( a local snack made from cooked maize and groundnut) and the motorbike was coming in between the cars. I didn't see it and so it knocked me down. After the incident, he just took his bike and drove off (Female, 32 years old).

Sometime last year. It occurred on a Sunday. Usually, I don't sell on Sundays, but a friend called to inform me that business was good that day so I should come. When I came, I sold a lot. Between the hours of $7 \mathrm{pm}$ and $8 \mathrm{pm}$, I saw one car towing another spoilt car. I couldn't tell that one was towing the other because the chains were so low and obviously because it was dark. I passed between them and the chain swept me down and the tyre of the spoilt car went over my leg (Female, 23 years old).

On the other hand, the other reported incidents happened by accident (misfortune), as they were beyond the control of the victims: 
About two years ago, I was standing here when a vehicle, which had lost control, knocked me down (Female, 48 years old).

A car hit me when I was trying to get out of its way. It so happened that it moved towards where I was running to (Female, 38 years old).

This, according to some hawkers represents the greatest traffic risk they face in the trade. Obviously, these experiences point to the inevitability of accident in the trade.

Moreover, we made a number of observations regarding street hawkers' road crossing and car-following behaviour. Firstly, we observed that fewer hawkers gave ample and informed consideration of the prevailing traffic situation before attempting any manoeuvre or crossing. Related to this, we noted a greater tendency for the youth $(\leq 30$-year-olds, both males and females) to indiscriminately cross the road. Underlying this behaviour is the desire to beat off competition from other hawkers to serve a potential buyer. As it is common to see a group of hawkers selling the same items, there is always that heightened competition to undo the other in order to make sales. This tendency for both genders to expose themselves to risk and be less cautious on the road is, however, inconsistent with the expectation that the male gender (i.e. male hawkers) will be the more active, risky (risk taker) and less cautious on the road. What makes this observed behaviour disturbing is that crossing road is one of the major actions of pedestrians associated with death and injuries in Ghana (NRSC, 2014).

Concerning the car-following behaviour, we observed a higher tendency for hawkers (especially the youth) to follow vehicles to the point where they satisfy their motive to sell to a buyer or retrieve payment for items already handed to the buyer (see Figure 2). This situation arises because some drivers refuse to heed to calls by passengers to stop for them to make purchases. We noted that brief vehicle stops, either for passengers to disembark or embark, and the presence of both the traffic light (at stop sign) and a toll booth present the opportunity for hawkers to transact business with the travelling public. As a whole, we 
observed that car-following and risky manoeuvres were prevalent during peak periods- both morning and evening rush hours, during which time business is at its peak.

\subsection{Traffic incidents involving other hawkers as reported by study participants}

Aside from their personal encounters, some participants also shared traffic incidents they had seen or been told involving other hawkers. These narratives were in response to the question 'Have you personally witnessed and/or heard about accidents involving other hawkers while hawking?'. The study noted eight of such encounters, some of which are reported below. However, 6 participants with personal accident encounters also reported some incidents they have heard (Table 4), one of which is reported here (last narrative).

I haven't personally witnessed an accident here before, but I was told about one that happened here some time ago. I hear it was terrible and lots of people died, about 18 people on the spot. I was told a Guinness truck run through the hawkers on the spot. It occurred on a Sunday (Female, 40 years old).

I have witnessed several hawkers knocked down by vehicles here. Some are back to business, others are unable to continue due to the gravity of the injuries they sustained (Female, 32 years old).

Several times; even a year ago a car knocked down someone and the person is still lying in bed unconscious and so a lot of accidents happen here. Just yesterday a female hawker had an accident here. She was selling and all we saw was she had fallen down and the car sped off. She got a big sore and her skirt was torn; all her wares were destroyed (Female, 32 years old). 
On the day of my accident, I heard there was another accident involving another hawker. He was knocked down by a motorcycle and a car passed on him and he died (Female, 23 years old).

\subsection{Relationship between socio-demographics and involvement in traffic incidents}

From our analysis, there seems to be a perceived relationship between the participants' sociodemographic characteristics, specifically gender, educational attainment and years of hawking, and personal encounters with traffic incidents. For example, of the 10 victims mentioned earlier, 8 were females and 2 males; half (5) had only had basic school education and 7 were relatively new to the trade ( $\leq 2$ years) at the time of their accident. Particularly, one of the victims was only a week old in the trade at the time of her accident. We recommend follow-up scientific study to explore further the perceived relationship between these variables. What makes these variables important is that they connote different traffic accident risks for road users. As alluded to above, there are gender differences regarding traffic risk perception, risk taking and risk handling abilities (Gustafson 1998; DeJoy, 1992; Yagil, 1998). Further, one's level of educational attainment (especially literacy level) may also influence his/her ability to understand road traffic rules and regulations, traffic risk and take appropriate actions. Also, educational attainment has an impact on road user behaviour in traffic (Najeeb, 2014). On the other hand, years of hawking denote exposure to the dangers of the road traffic environment, where the experienced street hawker is expected to be more abreast with the risk factors and may have developed the ability to handle such risks compared to a new hawker. A statement from a 44-year-old female hawker give credence to this notion: 
If you hear that a car has knocked someone down, then it means the person is a stranger (no experience or a beginner) who is passing through. This does not happen to us, the old ones.

\subsection{Hawkers' in-traffic survival strategies}

Given the enormity of the reported traffic incidents, we sought to assess the victims' experiences concerning post-accident treatment, compensation and ways of safeguarding their lives in traffic. Surprisingly, we noted that many of the victims received little or no attention from the offenders after their respective incidents. For example, a 23-year-old female hawker at Ngleshie Amanfrom recounted her ordeal:

The man (vehicle driver) said the authorities have cautioned us not to sell here and so he was not going to take responsibility. That day, he took me to a pharmacy around Mallam (a nearby town) for treatment and after my wound was dressed, he gave me 5 Ghana Cedis (GHC 3.5= US\$ 1 at that time) and left. That was it.

Yet another revealed: 'After the incident, he (motorcycle rider) just took his motorcycle and drove off. He uttered not a word to me' (Female hawker, 32 years, Kasoa).

Amidst the various risks faced in traffic by these hawkers, it is not surprising that they have in place survival strategies to safeguard their lives in traffic. One of such strategies is worthy of note:

Aside from being very careful in traffic, we have also sensitised ourselves that whoever senses danger, maybe vehicle loss of control, should unfailingly shout to alert colleagues so they can take cover (Female, 40 years, Ngleshie Amanfrom).

\subsection{Gender and age variations in traffic risk perception and handling}


Moreover, we sought to explore how gender and age influence street hawkers' traffic risk perception and handling abilities. Regarding gender, the interviews revealed that the male hawkers perceived less traffic risk in street hawking than their female counterparts as can be inferred from the following quotes:

It is dangerous to sell in the streets, but if I don't come, there will be no money for food for the family. Notwithstanding, one should be careful in traffic. If you see that the traffic is moving, then you move aside. Sometimes you will not notice and all of a sudden you will see the cars moving; the good drivers will wait for you to cross before they move (Female, 42 years old)

As for that (traffic risks), we face it every day. If this thing will happen, it will happen; if you are destined to die, you can even be in your room and if you will die, you will die (Male, 19 years old).

Earlier, we had observed him (the 19-year-old male hawker) escape from a car which moved towards his direction. We quizzed him on whether the car had lost control. His response (as quoted above), like those given by other male hawkers, denotes how they perceive risk in traffic, giving credence to previous findings by DeJoy (1992). DeJoy observed that males generally perceive traffic risk as less serious and less likely to result in accidents. Also, on traffic risk handling across gender, we found that male hawkers feel more capable than female hawkers in managing hawking-related traffic risks.

On the age variations in traffic risk perception and handling, we noted that youthful hawkers, unlike those in another group category, were less likely to perceive street hawking as risky and thus less worried about the supposed risks. Also, they feel more capable of managing unforeseen risks in traffic. This conviction predisposes them to unsafe traffic behaviours and disregard for danger signs in traffic (Otani et al., 1992). Our finding suggests a possible 
association between hawkers' traffic risk handling abilities and traffic risk perceptions. For instance, the more capable a hawker feels at managing hawking-related traffic risks, the less the risk perceived and the less concerned he/she becomes. However, this relationship seems to be mediated by gender and age as illustrated above. Further research is needed to explore and establish the exact nature and direction of this perceived relationship.

\section{Conclusion and further research}

To understand and expose the traffic risks involved in street hawking, this study sought street hawkers' lived experiences about road traffic incidents in the course of their trade. Traffic incidents involving other hawkers they know or might have heard about were also sought.

The study sample involved hawkers both males and females and of diverse ages. As the trade is both precarious and rigorous, it is uncommon to find the elderly (50 years and older). However, as there are more female hawkers than their male counterparts in reality, so the study participants were more likely to be females than males. Given the higher female representation in the study sample, it is not surprising a higher number of female participants reported involvement in previous accidents on the job.

On the basis of the evidence gathered by this study, the notion that hawking in traffic is risky is supported. However, we observed that the traffic risks associated with the trade are dictated by how street hawkers interact with the traffic environment, though unforeseen circumstances (e.g. driver and vehicle-related causes) can also play a role. For instance, a number of the reported incidents was caused largely by hawkers' negligence on the road which results in indiscriminate crossing and other related behaviours. Underlying the hawkers' indiscriminate road crossing and car-following behaviour was the heightened competition to sell to potential buyers and also the refusal by vehicle drivers to heed to passengers' call to make purchases. 
However, we noted a perceived relationship between hawkers' socio-demographic characteristics and personal encounters with traffic incidents. Also, hawkers' abilities to handle traffic risk seem to influence their traffic risk perception, even though gender and age seem to have a mediating role. Nevertheless, to bring closure to the issues raised in this study and also to explore the nature and direction of the supposed relationship between the reported variables, we strongly recommend further scientific (quantitative) study.

Furthermore, in spite of the traffic risks inherent in the trade, as narrated by the participants, the trade is thriving. This begs the question 'why are these people still in the business?' As this was beyond the focus of the present study, we recommend future studies to explore this in more detail.

Given the rather small sample size, we admit that the study findings cannot be generalised. Nevertheless, it reflects the lived experiences of the study participants regarding road traffic risks associated with hawking in traffic, especially along the Winneba-Kasoa highway. Also, as this study is exploratory, further scientific enquiry with a much larger sample is needed to explain the various issues exposed in this study. This will expose the frequency and magnitude of the traffic risks the hawkers face and thereby provide a more firm basis for appropriate interventions to manage the road safety implications of this activity.

\section{References}

Abane, A. M. (2010). Background characteristics and accident risk of commercial vehicle drivers in the Cape Coast-Elmina area of the Central Region, Ghana. Oguaa Journal of Social Sciences, 5(1), 64-86.

Adaawen, S. A. (2011). Street hawking and urban space regulation: The case of street hawkers in Accra, Ghana (Master's thesis, Norwegian University of Science and 
1

2

3

4

5

6

7

8

Technology, Norway). $\quad$ Retrieved from http://ntnu.divaportal.org/smash/get/diva2:542503/FULLTEXT02. Accessed 12 September 2016.

Asare, D. N. Y. B. (2010). A study of the street hawking phenomenon: A review of intervention programmes (Bachelor's dissertation). Ashesi University College, Ghana.

Ayodele, R. B. \& Olubayo-Fatiregun, M. A. (2014). Accidental injuries among juvenile hawkers: Clog in the wheel of sustainable socio-economic development of a nation. Asian Journal of Humanities and Social Sciences, 2(2), 19-30.

Beirao, G., \& Cabral, J. A. S. (2007). Understanding attitudes towards public transport and private car: A qualitative study. Transport Policy, 14, 478-489.

Building and Road Research Institute (2015). National road accident database. Kumasi, Ghana

Charmaz, K. (2006). Constructing grounded theory: A practical guide through qualitative analysis. Thousand Oaks, CA: Sage

Clifton, K.J., \& Handy, S.L. (2001). Qualitative methods in travel behaviour research. Retrieved from http://www.des.ucdavis.edu/faculty/handy/Qualitative_paper.pdf. Accessed 10 September 2016.

DeJoy, D. M. (1992). An examination of gender differences in traffic accident risk perception. Accident Analysis and Prevention, 24(3), 237-246.

Glaser, B. G., \& Strauss, A. L. (1967), The discovery of grounded theory: Strategies for qualitative research. Chicago: Aldine.

Gustafson, P (1998). Gender differences in risk perception: Theoretical and methodological perspectives. Risk Analysis, 18(6), 805-811.

Kwankye, S. O., Nyarko, P. E., \& Tagoe, C. A. (2007, December 10-14). Reproductive health implications of street hawking in Accra. Paper presented at the Fifth African 
Population Studies, Arusha, Tanzania. Retrieved from http://uaps2007.princeton.edu/papers/70103. Accessed 10 December 2014

Miles, M. A., \& Huberman, A. M. (1994). Qualitative data analysis: An expanded sourcebook (2nd Ed.). Thousand Oaks, CA: Sage.

Mitullah, W. V. (2003). Street vending in African cities: A synthesis of empirical findings from Kenya, Cote D'Ivoire, Ghana, Zimbabwe, Uganda and South Africa. Washington DC: World Bank.

Najeeb, M. (2014). A study of the psychological factors that influence the rule violation $\begin{array}{llll}\text { behaviour } & \text { of } & \text { drivers. } & \text { Retrieved }\end{array}$ http://www.ictct.org/migrated_2014/ictct_document_nr_906_Najeeb.pdf. Accessed 20 October 2016

National Road Safety Commission. (2010). National road accident report. Accra: Author National Road Safety Commission. (2014). National road accident report. Accra: Author Nduka I. \& Duru, C. O. (2014). The menace of street hawking in Aba metropolis, South-East Nigeria. Journal of Medicine and Medical Sciences, 5(6), 133-140.

Obiri-Asare, S. (2016). Accra-Cape Coast dualization project. Retrieved from http://www.business-funding-insider.com/accracapecoast-dualization-project.html. Accessed 24 June 2017.

Otani, H., Leonard, S. D., Ashford, V. 1., Bushroe, M., \& Reeder, G. (1992). Age differences in perception of risk. Perceptual and Motor Skills, 74(2), 587-94).

Patton, M. Q. (1990). Qualitative research and evaluation methods (3rd Ed.). Newbury Park, CA: Sage.

Sam, E. F. (2011). Determinants of road traffic crashes on the Accra-Cape Coast highway in Ghana (Master's thesis). University of Cape Coast, Ghana. 
Sandelowski, M. (1995). Focus on qualitative methods: Sample size in qualitative research. Research in Nursing, 18, 179-183.

Sandelowski, M. (2000). Focus on research methods: Combining qualitative and quantitative sampling, data collection, and analysis techniques in mixed-method studies. Research in Nursing \& Health, 23, 246-255.

Sivak, M., Soler, J., Trankle, U., \& Spagnhol, J. M. (1989). Cross-cultural differences in driver risk-perception. Accident Analysis and Prevention, 21(4), 355-362.

Skinner, C. (2008). Street trade in Africa: A review. Cambridge, MA: WIEGO

Steel, W. F., Ujoranyi, T. D., \& Owusu, G. (2014). Why evictions do not deter street traders: Case study in Accra, Ghana. Ghana Social Science Journal, 11(2), 52-76.

Yagil, D. (1998). Gender and age-related differences in attitudes toward traffic laws and traffic violations. Transportation Research Part F, 1, 123-135.

\section{Appendices}

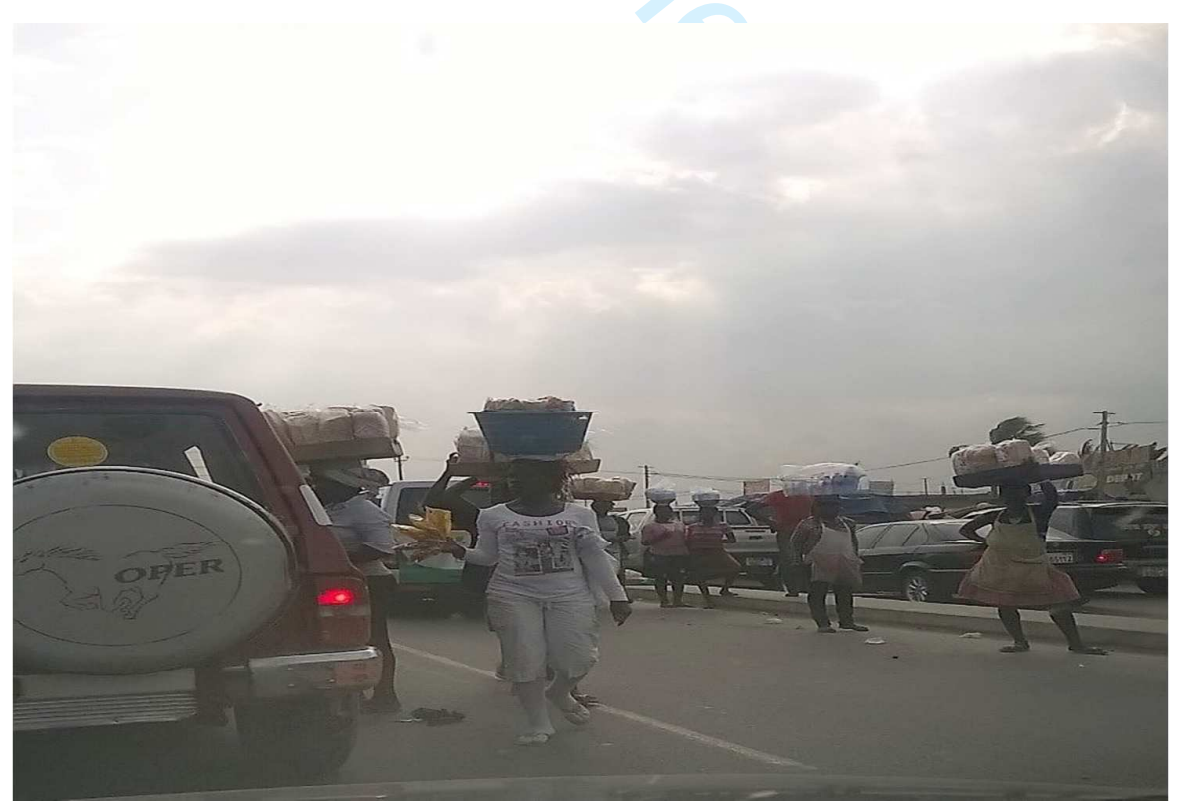

Figure 1: Street hawkers in their line of business (evening peak hour) 


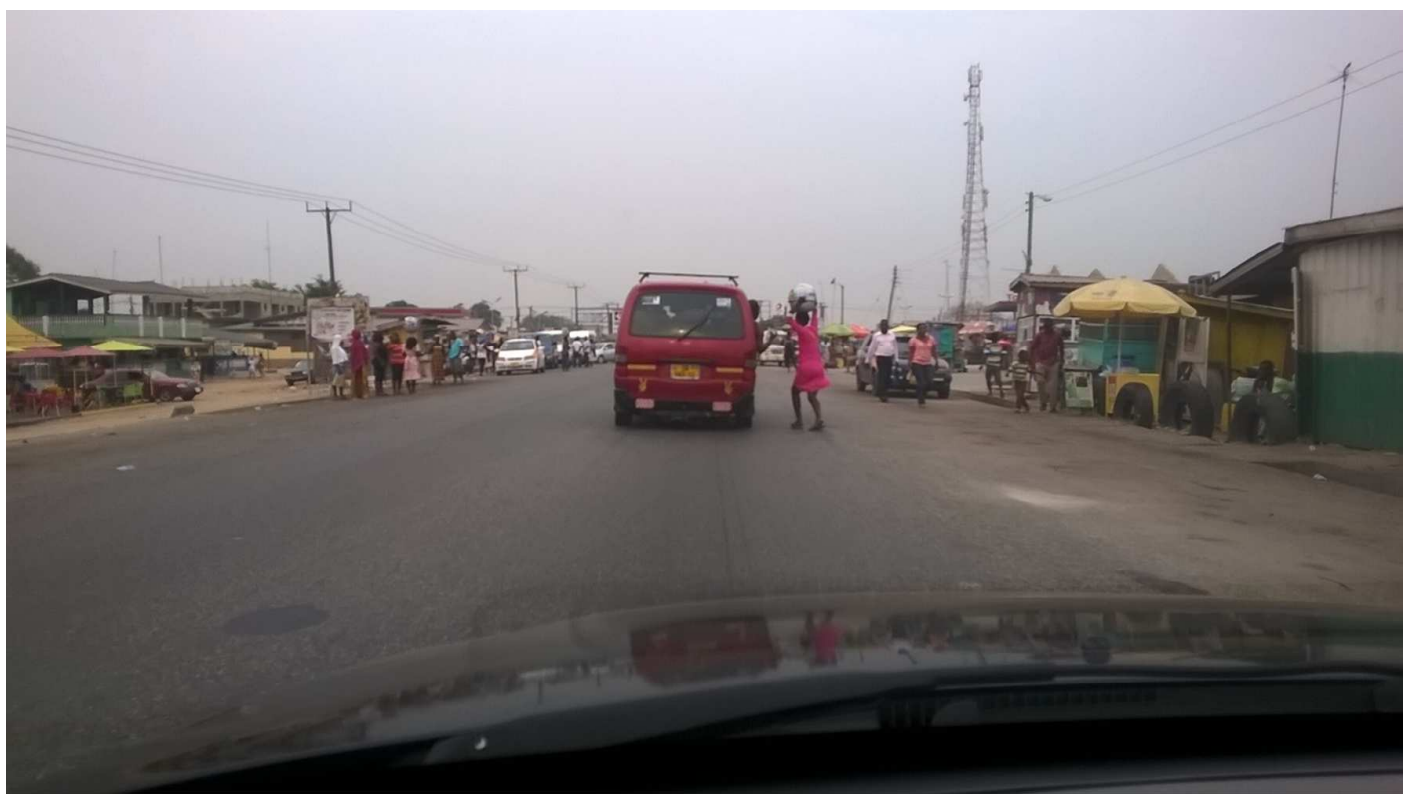

Figure 2: A female (youth) hawker selling to a passenger while the vehicle was in motion (off-peak hour)

Table 1: Road traffic accident severity by study sites, 2010

\begin{tabular}{lccccc}
\hline Site & Fatal & Serious & Slight & Damage only & Total \\
\hline Kasoa road & 2 & 7 & 16 & 14 & 39 \\
Ngleshie Amanfrom & 2 & 4 & 4 & 7 & 17 \\
Winneba junction & 1 & 4 & 1 & 2 & 8 \\
\hline
\end{tabular}

Source: Extracted from national accident statistics

Table 2: Field observations and notes

\begin{tabular}{lllll}
\hline Incidents & $\begin{array}{l}\text { Incidents } \\
\text { observed }\end{array}$ & Remark/note & \\
\hline Car following & 15 & $\begin{array}{l}\text { Intense during peak hours. } \\
\text { More akin to youthful } \\
\text { hawkers. }\end{array}$ \\
Indiscriminate crossing/ running across 11 & Many hawkers & seem \\
\hline
\end{tabular}




\begin{tabular}{|c|c|c|}
\hline the road & & $\begin{array}{l}\text { unconcern when crossing the } \\
\text { road, especially during peak } \\
\text { hours. Greater tendency for } \\
\text { youthful hawkers was } \\
\text { observed. This is basically in } \\
\text { response to calls by potential } \\
\text { buyers }\end{array}$ \\
\hline $\begin{array}{l}\text { Hawker-other road user (e.g. motor } \\
\text { vehicle) conflicts }\end{array}$ & 4 & $\begin{array}{l}\text { Mainly took the form of who } \\
\text { (hawker vs vehicle user) has } \\
\text { the right of way. Traffic flow } \\
\text { was impeded in many } \\
\text { instances. }\end{array}$ \\
\hline Near accidents/Hawker dart-outs & 1 & $\begin{array}{l}\text { Observed an evasive action by } \\
\text { a hawker in an attempt to } \\
\text { escape a vehicle which had } \\
\text { lost control. }\end{array}$ \\
\hline
\end{tabular}

Table 3: Participants' characteristics

\begin{tabular}{lclr}
\hline Variable & Number & Variable & Number \\
\hline Gender & 6 & Marital status & \\
Male & 18 & Single & 12 \\
Female & & $\begin{array}{l}\text { Married } \\
\text { Divorced }\end{array}$ & 3 \\
& & & \\
Age & 5 & Years hawking & 2 \\
$10-20$ & 8 & $<1$ year & 13 \\
$21-30$ & 8 & $1-5$ years & 4 \\
$31-40$ & 3 & $6-10$ years & 4 \\
$41-50$ & & $11-20$ years & 1 \\
& & $21-30$ years & \\
Education & & & \\
(attained) & & & \\
No formal & 5 & & \\
Basic/ Primary & 6 & & \\
Junior high school & 10 & & \\
\hline
\end{tabular}




\section{Senior high school 2}

Vocational/Technical 1

Table 4: Frequency with which each theme was reported (groundedness)

\begin{tabular}{ll}
\hline Theme & $\mathrm{N}$ \\
\hline Participants' personal traffic incidents & 10 \\
Traffic incidents involving other hawkers as narrated by study participants & 14 \\
Hawkers' in-traffic survival strategies & 10 \\
Gender and age variations in traffic risk perception and handling & 6
\end{tabular}

